\title{
First Record of Terrestrial Talitrid Amphipod (Crustacea: Amphipoda: Talitridae) from Korea
}

\author{
Min-Seop Kim and Gi-Sik Min* \\ Department of Biological Sciences, College of Natural Sciences, Inha University, \\ Incheon 402-751, Korea
}

\begin{abstract}
A terrestrial talitrid amphipod, Platorchestia japonica (Tattersall, 1922), has been recorded for the first time from Korea. This species was collected from riversides (Han River, Bukhan River and Hantan River) in Korea. Descriptions of diagnostic characters of the species are provided in the text. A key to the four species of Korean Platorchestia is also provided.
\end{abstract}

Keywords: Talitridae, terrestrial talitrid, Platorchestia japonica, first record, Korea

\section{INTRODUCTION}

The genus Platorchestia Bousfield, 1982 (Amphipoda, Crustacea), is one among 52 genera belonging to the family Talitridae, and 16 species in the genus showing worldwide distribution have been reported to date (Serejo and Lowry, 2008). This taxon is found at the shores of rivers and coastal areas, in areas including supralittoral zones, grass lands, and small patches of leaf-litter, on both mainland and islands (Miyamoto and Morino, 2004).

Three species of Platorchestia were reported by Jo (1988) in Korea: P. crassicornis (Derzhavin, 1937), P. munmui Jo, 1988 and $P$. pachypus (Derzhavin, 1937). Including $P$. japonica (Tattersall, 1922), a terrestrial talitrid amphipod reported in this study, four Platorchestia species are known to be among Korean fauna.

Samples were preserved in $95 \%$ ethyl alcohol immediately upon collection. Specimens were observed under a stereomicroscope (Olympus, SZX 12) and a light microscope (LEICA, DM 2500). All dissected appendages were mounted on glycerin and were stained by Lignin Pink. Consecutive digital images on different focal planes (usually 3 or more shots per slide) were taken using a microscope digital camera (Moticam 2000) and the images were Z-stacked using Helicon Focus ${ }^{\circledR}$ software (Helicon Soft, Ltd). The specimens were classified by the method described by Serejo and Lowry (2008). The voucher specimens collected and studied herein have been deposited in the Department of Biological Sciences, Inha University, South Korea.

*To whom correspondence should be addressed

Tel: 82-32-860-7692, Fax: 82-32-874-6737

E-mail: mingisik@inha.ac.kr

\section{SYSTEMATIC ACCOUNTS}

Order Amphipoda Latreille, 1816

Family Talitridae Costa, 1857

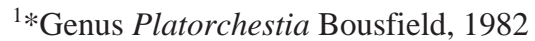

2*Platorchestia japonica (Tattersall, 1922) (Figs. 1-4)

Talorchestia japonica Tattersall, 1922, p. 452, pl. XXI, figs. 1-10.

Platorchestia japonica Bousfield, 1982, p. 27; Morino and Dai, 1990, p. 21, figs. 9-11; Morino, 1999, p. 626; Hou and Li, 2003, p. 2441, figs. 1-4; Miyamoto and Morino, 2004, p. 70, figs. 8-10.

Material examined. Two males and four females (one male and one female are shown in images presented in this paper):

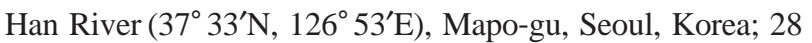
Mar. 2009; collected by Min-Seop Kim. Other materials from the following localities were also examined. Two males and three females: Hantan River $\left(38^{\circ} 01^{\prime} \mathrm{N}, 127^{\circ} 04^{\prime} \mathrm{E}\right)$, Jeongogeup, Yeoncheon-gun, Gyeonggi-do, Korea; 5 May 2009; collected by Min-Seop Kim. Three males and four females: Bukhan River $\left(37^{\circ} 32^{\prime} \mathrm{N}, 127^{\circ} 18^{\prime} \mathrm{E}\right)$, Joan-myeon, Namyangju-gun, Gyeonggi-do, Korea; 9 Apr. 2009; collected by MinSeop Kim.

Description of male. Head (Figs. 1, 2A): body length 12.8 $\mathrm{mm}$, eyes subround, width about 0.45 times head diameter; interior antennal sinus distinct; buccal mass directed below head.

Antenna 1 (Fig. 2A, B): antenna 1 not reaching end of peduncle article 5 of antenna 2 ; peduncle articles $1-3$ in length ratio $1: 0.7: 0.7$, with distal setae; flagellum with 4 articles.

$1 *$ 도약옆새우속(신칭), ${ }^{2 *}$ 강변도약옆새우(신칭) 


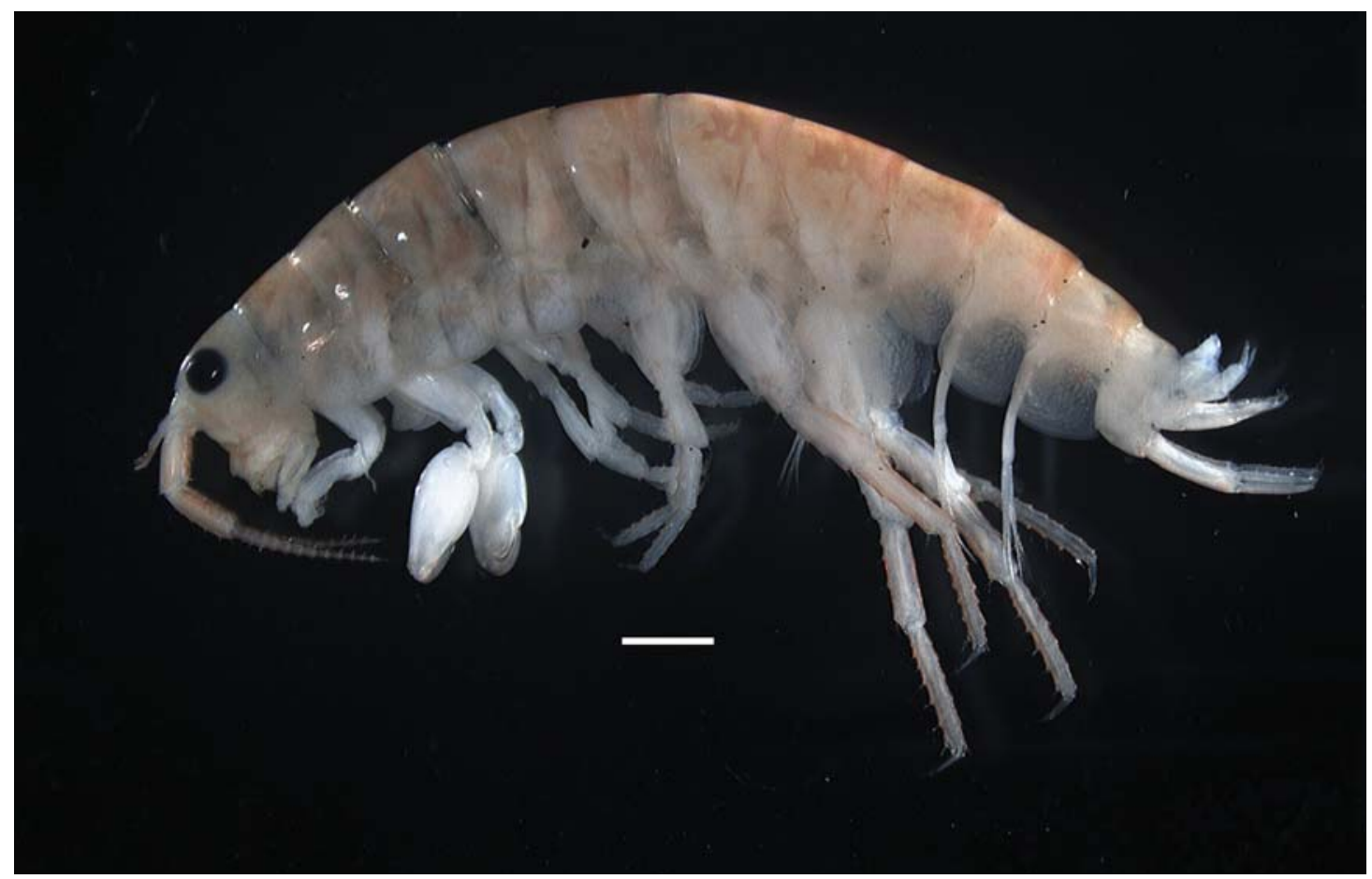

Fig. 1. Platorchestia japonica, male (lateral view). Scale bar=1 mm.

Antenna 2 (Fig. 2C): peduncle article 4-5 in length ratio 1 : 1.4, with short spines along both margins; flagellum 13 articles, each article with short distal setae.

Upper lip (Fig. 2D): convex, with fine setae.

Mandible (Fig. 2E, F): left incisor 5 dentate, lacinia mobilis with 5 week teeth, molar triturative with 1 plumose seta; right incisor 5 dentate, lacinia mobilis bifurcate with many weak dentitions apically.

Lower lip (Fig. 2G): concave, with minute setae, inner plate absent.

Maxilla 1 (Fig. 2H, I): inner plate with 2 plumose setae; outer plate having 9 saw-like spines on distal margin; palp minute, with 2 articles.

Maxilla 2 (Fig. 2J): inner plate with 1 large plumose seta at medial margin, bearing article setae; outer plate with 2 rows of distal setae.

Maxilliped (Fig. 2K): inner plate with 3 blunt apical spines; article 4 of palp projected beyond article 3 , with a few distal spines.

Gnathopod 1 (Fig. 2L, M): lower margin of coxal plate rounded, with 5 spines and 1 fine seta; basis straight, bearing 6 short spines on inner margin and 1 short spine on outer margin; merus with 6 short spines on posterior margin; carpus and propodus tumescent posteriorly, propodus about 0.65 times as long as carpus, with rows of spines, palmar margin with some setae and spines; dactylus slightly shorter than palm of propodus.

Gnathopod 2 (Fig. 2N, O): coxal plate with cuspidate posterior margin; lower margin spinulose; basis anterior margin bare, posterior margin with 3 short spines; propodus oval in shape, palmar margin smoothly convex, fringed with many short spines.

Pereopod 3-4 (Fig. 3A-D): pereopod 3 longer than pereopod 4, posterior margin of coxal plates with small cusp; both anterior and posterior margin of merus to propodus with some spines; dactylus with 1 stiff seta on concave margin; pereopod 4 similar to pereopod 3, but carpus short.

Pereopods 5-7 (Fig. 3E-K): anterior lobe of coxal plate 5 broader than posterior lobe, coxal plate 6 posterolobate and coxal plate 7 non-lobate; posterior margin of basis with a row of several fine setae, anterior margin bearing spines; anterior margin of merus to propodus with more spines than posterior margin; dactylus with 1 stiff seta near hinge of nail.

Epimeral plates 1-3 (Fig. 3L): epimeral plates with weakly pointed posterior angles, ventral margin unarmed and posterior margin bearing several fine setae.

Pleopods 1-3 (Fig. 3M, O-Q): pleopods well developed, peduncles with two retinaculae; both rami with about 9-12 articles, fringed with plumose setae.

Uropod 1 (Fig. 3R): peduncle longer than rami, with short distolateral spines; outer ramus slightly shorter than inner ramus, outer ramus marginally bare; inner ramus with 1 and 

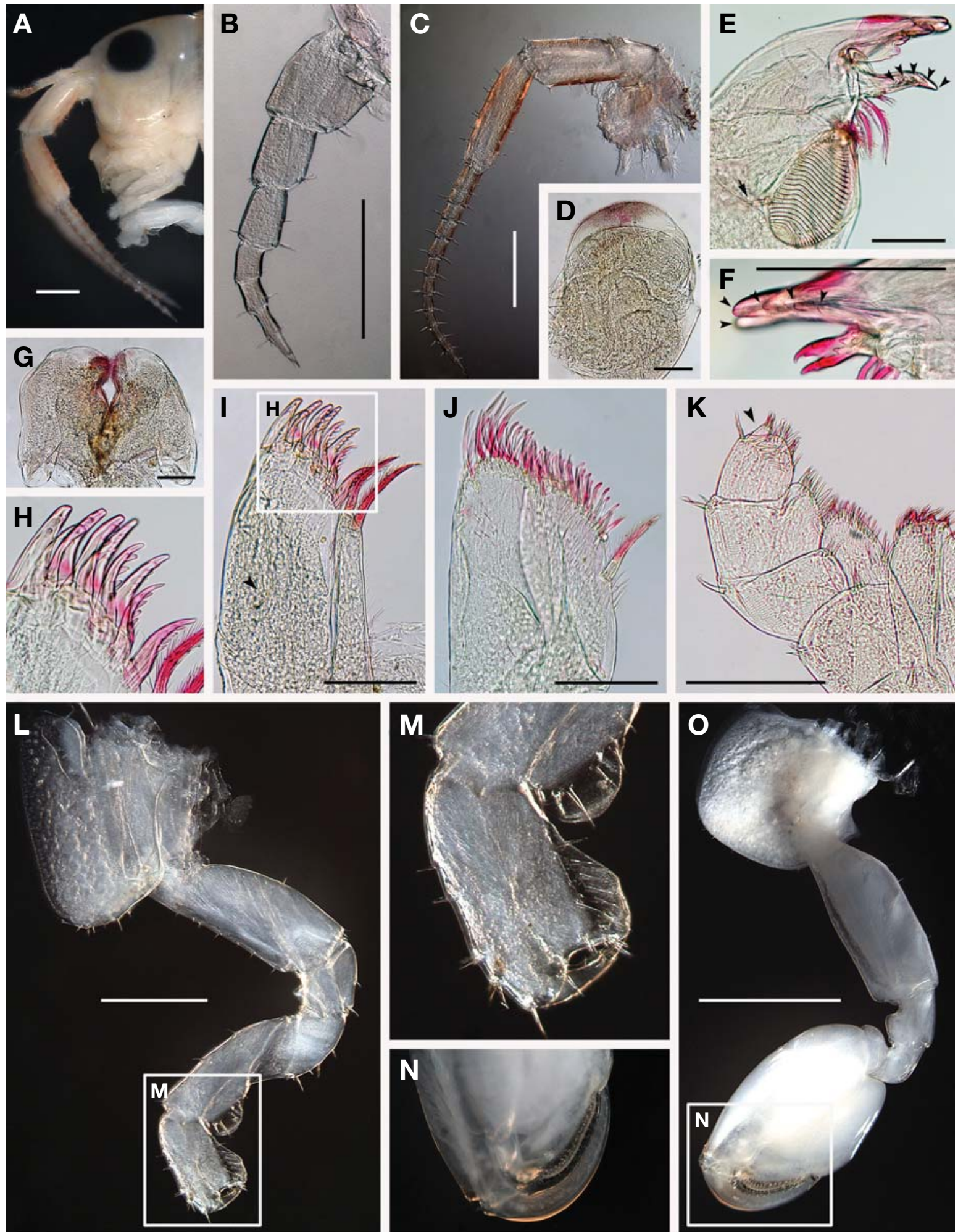

Fig. 2. Platorchestia japonica, male: $A$, head; $B$, antenna $1 ; C$, antenna $2 ; D$, upper lip; $E$, left mandible, arrows indicate lacinia mobilis (arrowheads) and plumose seta (arrow); $F$, incisor of right mandible, arrowheads shows incisor dentate; $G$, lower lip; $H$, serrated spines of maxilla $1 ; \mathrm{I}$, maxilla 1 , arrowhead indicate rudimentary palp; J, maxilla $2 ; \mathrm{K}$, maxilliped, arrowhead indicate article $4 ; \mathrm{L}$, gnathopod $1 ; \mathrm{M}$, propodus of gnathopod $1 ; \mathrm{N}$, propodus of gnathopod $2 ; \mathrm{O}$, gnathopod 2 . Scale bars=1 mm $(A, L, O), 0.5 \mathrm{~mm}$ $(B, C), 125 \mu \mathrm{m}(D-G, I-K)$. 

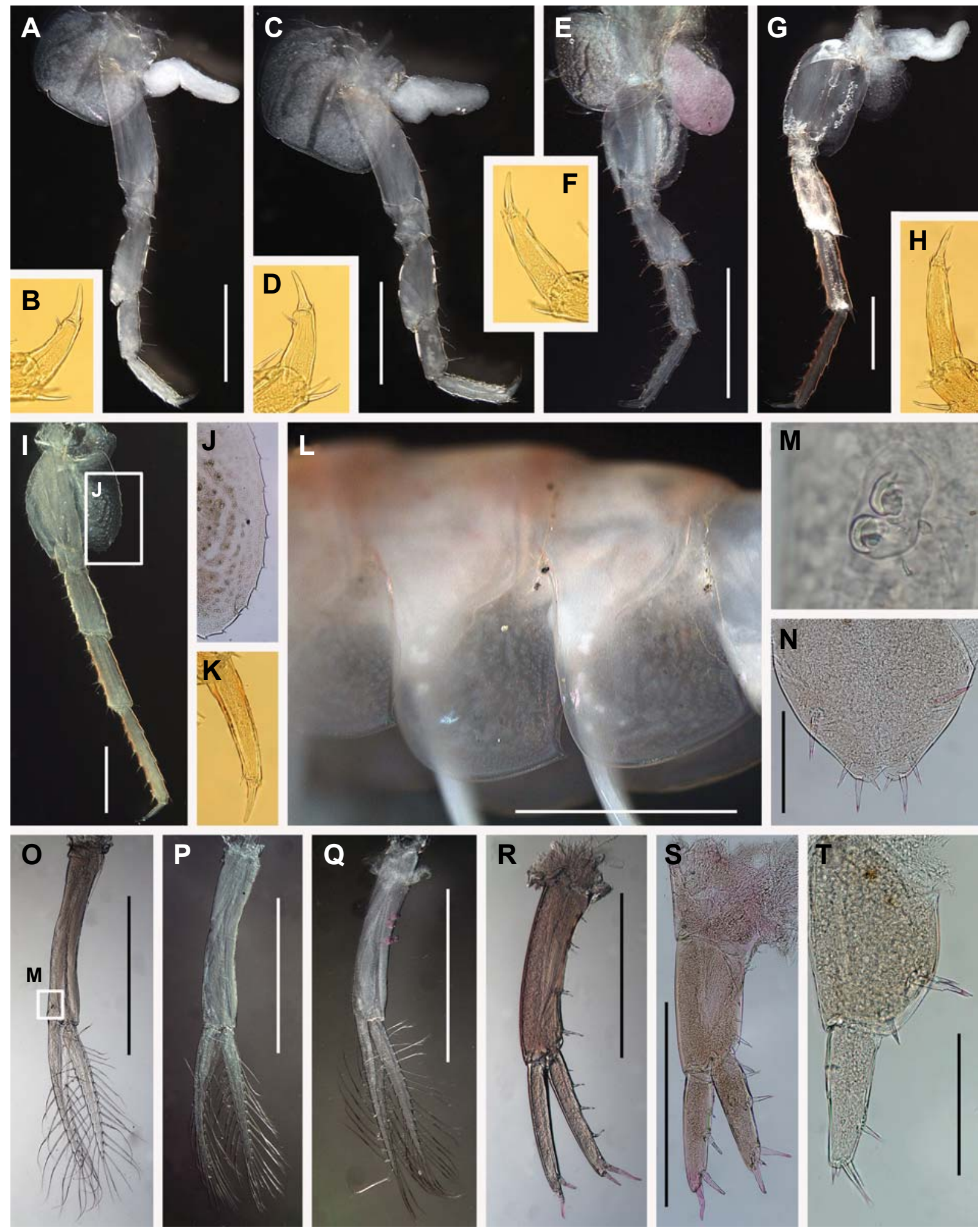

Fig. 3. Platorchestia japonica, male: A, pereopod 3; B, dactylus of pereopod 3; C, pereopod 4; D, dactylus of pereopod 4; E, pereopod $5 ; \mathrm{F}$, dactylus of pereopod $5 ; \mathrm{G}$, pereopod $6 ; \mathrm{H}$, dactylus of pereopod 6 ; $\mathrm{I}$, pereopod $7 ; \mathrm{J}$, posterior margin of basis in pereopod 7; $\mathrm{K}$, dactylus of pereopod $7 ; \mathrm{L}$, epimeral plates; $\mathrm{M}$, retinacula of pleopod $1 ; \mathrm{N}$, telson; O, pleopod 1; P, pleopod 2; Q, pleopod 3; R, uropod $1 ; \mathrm{S}$, uropod 2; T, uropod 3. Scale bars $=1 \mathrm{~mm}(\mathrm{~A}, \mathrm{C}, \mathrm{E}, \mathrm{G}, \mathrm{I}, \mathrm{L}, \mathrm{O}-\mathrm{S}), 250 \mu \mathrm{m}(\mathrm{N}, \mathrm{T})$. 

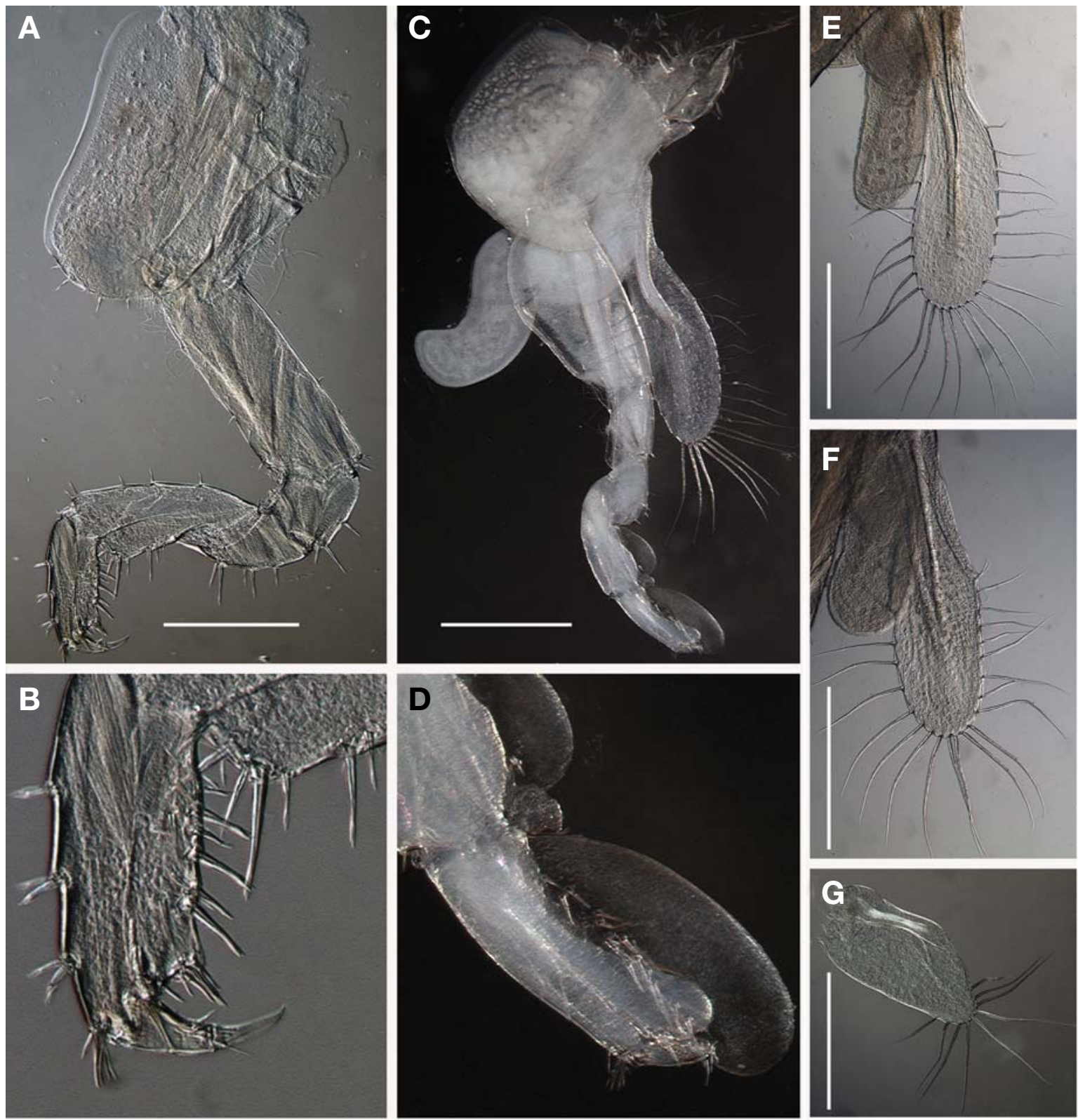

Fig. 4. Platorchestia japonica, female: $A$, gnathopod $1 ; B$, propodus of gnathopod $1 ; C$, gnathopod $2 ; D$, propodus of gnathopod 2 ; E, oostegite of pereopod 3; F, oostegite of pereopod 4; G, oostegite of pereopod 5 . Scale bars=1 mm (A, C, E-G).

3 spines on inner and outer margins, respectively; both rami with distal spines.

Uropod 2 (Fig. 3S): peduncle a little longer than rami, with several spines on inner and outer margins; inner ramus with 2 marginal and 3 distal spines, outer ramus with 1 inner marginal and 2 outer marginal, 4 distal spines.

Uropod 3 (Fig. 3T): peduncle with 2 lateral and 1 distal spine, ramus slightly shorter than peduncle, bearing 1 lateral and 4 distal spines.

Telson (Fig. 3N): apically notched, each lobe with 3 distal spines and 1 sublateral spine.

Description of female. General appearance similar to male. Differs as follows:

Gnathopod 1 (Fig. 4A, B): carpus and propodus without tumescent humps; propodus with many spines on posterior margin, palmar margin short; dactylus exceeding palmar margin.

Gnathopod 2 (Fig. 4C, D): coxal plate with cuspidate posterior margin; basis anteriorly broadened, anterior margin with many minute spines evenly, posterior margin with few 
spines; merus with small facial spines; carpus and propodus tumescent posteriorly; propodus with spine-row on lateral surface, palm margin with five stiff setae; dactylus about half of palmar margin, with a seta at hinge of nail.

Oostegites (Fig. 4C, E-G): oostegites of pereopods 2-4 elongate, parallel-sided, with dozens of setae; oostegite of pereopod 5 triangular, with 10 setae on distal margin and two spines on surface.

Habitat. This landhopper is distributed along the Han River, Bukhan River and Hantan River in Korea. Specimens were found under rotting hay or in silt beside the water.

Remarks. Three species of Platorchestia have been reported in Korea. They were found only in coastal areas. However $P$. japonica, reported in this study, was collected from the silt along inland rivers in Korea. Therefore, $P$. japonica is the first actual terrestrial talitrid species reported in Korea.

Platorchestia japonica is morphologically similar to $P$. humicola (Martens, 1868) in the following characters: antenna 2 and pereopod 7 weakly sexually dimorphic; palm of male gnathopod 2 smoothly convex. However, the two species showed the following differences: the length ratio between rami and peduncle of pleopod was 0.8-0.9 in $P$. japoni$c a$, while in $P$. humicola that was 0.5-0.6; the uropod 3 of $P$. japonica has 2 long and a few distal short spines, but $P$. humicola showed one long and a few distal short ones.

Platorchestia japonica are distributed in Japan (Tattersall, 1922; Morino, 1999), China (Morino and Dai, 1990; Hou and Li, 2003) and Taiwan (Miyamoto and Morino, 2004). The features of Korean $P$. japonica accord well with previously identified specimens. However, the Korean specimens showed the following differences from those of other countries: number of lateral spines on peduncle of uropod 3; number of dorsal and distal spines on each lobe of telson.

Four known species of Korean Platorchestia can be distinguished by the following key.

\section{Key to four species of Platorchestia in Korea}

1. Antenna 2 and pereopod 7 strongly sexually dimorphic; flagellum of antenna 2 (male) is 0.9-1.5 times as long as peduncular article 5; inner plate of maxilla 2 with 20-30 blunt spines on distal margin; propod of male gnathopod 1 with bifid spines on lateral surface; palm of male gnathopod 2 sinuous or with protuberance $\ldots \ldots \ldots \ldots \ldots \ldots \ldots \ldots \ldots \ldots \ldots \ldots \ldots$

- Antenna 2 and pereopod 7 weakly or barely sexually dimorphic; flagellum of antenna 2 (male) is 1.8-2.2 times as long as peduncular article 5 ; inner plate of maxilla 2 with 15-20 blunt spines on distal margin; propod of male gnathopod 1 without bifid spines on lateral surface; palm of male gnathopod 2 smoothly convex

P. japonica (Tattersall, 1922)

2. Gnathopod 1 of male, dactyl distinctly or slightly shorter than total palm; dactylus with scale-like denticle antero-

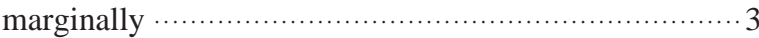

- Gnathopod 1 of male, dactyl slightly longer than total palm; dactylus lacking denticle

P. crassicornis (Derzhavin, 1937)

3. Pereopod 7, width of carpus subequal to merus; left lacinia 6 dentate of mandible ….............. P. munmui Jo, 1988.

- Perepod 7, carpus much broader than merus; left lacinia 6 dentate of mandible ….... P. pachypus (Derzhavin, 1937)

\section{ACKNOWLEDGEMENTS}

This work was supported by Inha University.

\section{REFERENCES}

Bousfield, E.L., 1982. The amphipods superfamily Talitroidea in the northeastern Pacific Region. 1. Family Talitridae: systematics and distributional ecology. Natl. Mus. Nat. Sci., 11: 1-73.

Derzhavin, A.Y., 1937. Talitridae of the Soviet coast of the Japan Sea. Issl. Morej SSSR, 23: 87-112.

Hou, Z.E. and S.Q. Li, 2003. Terrestrial talitrid amphipods (Crustacea: Amphipoda) from China and Vietnam: studies on the collection of IZCAS. J. Nat. Hist., 37(20): 2441-2460.

Miyamoto, H. and H. Morino, 2004. Taxonomic studies on the Talitridae (Crustacea, Amphipoda) from Taiwan. II. The genus Platorchestia. Publ. Seto Mar. Biol. Lab., 40(1/2): 67-96.

Morino, H., 1999. Amphipoda. In: Pictorial keys to soil animal of Japan (Ed., J. Aoki). pp. 626-644. Tokai University Press.

Morino, H. and A.Y. Dai, 1990. Three amphipod species (Crustacea) from East China. Pub. Itako Hydrobiol. Stn., 4: 7-27.

Serejo, C.S. and J.K. Lowry, 2008. The Coastal Talitridae (Amphipoda: Talitroidea) of Southern and Western Australia, with Comments on Platorchestia platensis (Kroyer, 1845). Rec. Aust. Mus., 60(2): 161-206.

Tattersall, W.M., 1922. Zoological results of a tour in the Far East. Amphipoda with notes on an additional species of Isopoda. Mem. Asiat. Soc. Bengal, 6: 437-459.

Received February 24, 2010 Accepted March 11, 2010 